\title{
GCU
}

Glasgow Caledonian

University

University for the Common Good

\section{Constructing the durable penal agent: tracing the development of habitus within English probation officers and Scottish criminal justice social workers}

\author{
Grant, Scott
}

Published in:

British Journal of Criminology

DOI:

10.1093/bjc/azv075

Publication date:

2016

Document Version

Author accepted manuscript

Link to publication in ResearchOnline

Citation for published version (Harvard):

Grant, S 2016, 'Constructing the durable penal agent: tracing the development of habitus within English

probation officers and Scottish criminal justice social workers', British Journal of Criminology, vol. 56, no. 4, pp. 750-768. https://doi.org/10.1093/bjc/azv075

\section{General rights}

Copyright and moral rights for the publications made accessible in the public portal are retained by the authors and/or other copyright owners and it is a condition of accessing publications that users recognise and abide by the legal requirements associated with these rights.

Take down policy

If you believe that this document breaches copyright please view our takedown policy at https://edshare.gcu.ac.uk/id/eprint/5179 for details of how to contact us. 


\title{
Constructing the durable penal agent: tracing the development of habitus within English probation officers and Scottish criminal justice social workers
}

\author{
Scott Grant (Glasgow Caledonian University)
}

\begin{abstract}
In contrast to prison personnel, practice cultures of penal agents charged with delivering 'community punishment' are surprisingly under-researched. Recent evidence from Scotland and England suggests that community-based penal agents demonstrate strong capacities for resistance against state-level punitive discourse. This indicates that despite several turns in penal policy, successive UK Governments have failed to produce tougher systems of community punishment as intended. By deploying Bourdieu's conceptual tools of habitus and field, and referring to evidence from empirical studies, this article will attempt to show that penal agents possess durable and deeply embedded dispositions that not only protect them from punitive field conditions, but also guide and underpin their everyday practice with offenders. By doing so, this article offers a conceptual starting point for an emerging sociology of community punishment.
\end{abstract}

Key words: habitus, probation, criminal justice social work, community punishment, Bourdieu.

\section{Introduction}

In 2011, the English and Welsh Probation Service won the British Quality Foundation's 'Gold Medal for Excellence' - a noteworthy first for a public sector organisation in the UK. In July 2013, all probation trusts in England and Wales were rated as either 'good' or 'exceptional' by the National Offender Management Service (NOMS, 2013). Re-offending rates, for those subject to community-based orders, had reduced by six percentage points in the period from 2002 to 2013; the average number of re-offences per offender had reduced by $24.2 \%$ over the same period (Ministry of Justice, 2015). And yet, despite these official indicators of success in both policy outcomes and practice performance the Ministry of Justice (MoJ), believing that reoffending had simply been 'too high for too long', published plans, in May 2013, for substantial changes to be made in the delivery of probation services in England and Wales (see Transforming Rehabilitation: A Strategy for Reform, MoJ, 2013). Perhaps the most contentious aspect of these plans is the part-privatisation of key probation 
functions. On June $1^{\text {st }} 2014$, the responsibility for managing low- to medium-risk offenders was transferred to 21 privately-owned Community Rehabilitation Companies (CRCs) who will, by contract, receive 'payment by results' from the Ministry of Justice. Responsibility for high-risk offenders will remain within public sector control as a primary function of a pared-back National Probation Service. In contrast, there are no immediate or future plans to privatise any part of criminal justice social work in Scotland. But for those English and Welsh penal agents (probation officers and associated staff) currently working in community settings, this is, undoubtedly, a more turbulent time in their history.

Indeed, the brunt of political maneuvering, incessant restructuring and constant shifts in penal policy (in both jurisdictions) have led scholars, more recently, to focus on the impact of these fluctuations upon different facets of penal-professional practice in community settings. These include: enforcement issues (Robinson and Ugwudike, 2012; Ugwudike, 2011); motivations of students and newly-qualified practitioners (Annison et al., 2008; Deering, 2010); occupational cultures (Deering, 2011; Mawby and Worrall, 2013); the impact of structured programmes and the use of skills (Raynor and Vanstone, 1997; Raynor et al., 2010; 2013); constructions of 'quality' in routine practice (Grant and McNeill, 2014a; 2014b; Robinson et al., 2013); and the increasing impact and use of assessment tools (Mair et al., 2006; Robinson, 2003). And whilst other punishment scholars have focused specifically on the role of penal agents inside prison settings (such as Crewe, 2011; Lerman and Page, 2012; Liebling, 2000), in comparison, and despite the literature mentioned so far, very few empirical studies have examined the practice cultures of penal agents in community-based settings (Burke and Davies, 2011).

Of those empirical studies that do exist, some either explicitly or implicitly suggest that community-based penal-professional agents across the UK demonstrate strong and durable degrees of commitment to welfare-oriented approaches in their everyday practice (See: Annison, 2006; Deering, 2010; Ditton and Ford, 1994; Eadie and Winwin Sein, 2004; Grant and McNeill, 2014a; Knight, 2007; McNeill et al., 2009; Robinson and McNeill, 2004; Worrall and Mawby, 2014). Some of these studies, as we shall see, point toward, as well as suggest, something more about the dispositional make-up of penal-professional agents; indeed, findings seem to indicate a pattern in the value of certain qualities that appear to give penal agents durability in the face of incessant penal change. It is worth noting here that despite significant areas of convergence in, for example, practice skills (See Raynor and Vanstone, 2015), literature on English and Welsh probation currently outweighs that on Scottish criminal justice social work. This imbalance means that assertions and conclusions in this article are drawn more from English and Welsh sources, but reference is made to examples of Scottish 
research throughout. This article will also consider brief but relevant examples of international evidence, exploring transferability where applicable.

So, with a particular focus on dispositions, this article will attempt to make a more substantial contribution to an emerging sociology of community punishment by using conceptual tools provided by Bourdieu for the purpose here of exploring how and why penal agents in different jurisdictions are able to practise in ways that seem capable of resisting the punitive field conditions in which they work. By referring to what we know already about occupational cultures of probation and criminal justice social work, this article will start by exploring empirical evidence from different studies where dispositions have been mentioned or featured amongst other findings, before exploring the development of these dispositions (habitus) in penal agents through subsequent stages of primary and secondary formation. As no empirical study has looked specifically at dispositions of penal agents in the UK, the first part of this article will draw on evidence under thematic headings where research has focused on (a) agents during training and those newly-qualified; (b) experienced agents in practice; and (c) agents working in different jurisdictions. This article will conclude by exploring how the dispositions of penal agents are affected by the social space (or field) in which they, as practitioners, have a significant yet underplayed position. In doing so, this article hopes to provide a starting point for further empirical research and conceptual development in this emerging area.

\section{Trainees and newly-qualified penal agents}

Starting with studies of penal agents either in training or those newly-qualified, findings here suggest that a firm majority wanted to do this type of work as they felt intrinsically motivated to help people change, believing it to be meaningful, and therefore satisfying as a career choice. Knight (2007), for example, conducted a quantitative study of what motivated people to enter a career in probation. This study included a sample of 257 Diploma in Probation Studies (DipPS) applicants and existing probation students. Knight (2007) found that over $90 \%$ of participants rated items such as people centered and wants to help people change as being key factors in their decision to pursue a probation career. Even when asked about more punitive dimensions to the probation role such as authority and control, Knight (2007) found that responses favoured more welfare-oriented factors such as problem solving and facilitating change. Similar results are found in studies conducted by Eadie and Winwin Sein (2004) who focused on trainee probation officers $(n=262)$, and Annison (2006) who sought the views of DipPS graduates $(n=77)$. Both studies are conflated in a separate article by Annison et al. (2008) who found that despite significant transformation in the probation service (in England \& Wales) between 2001 (when the National Probation Service formed) and 2004 (with the establishment of the National Offender Management 
Service), the perceived shift from 'welfare-focused interventions' to rehabilitation recast as 'reducing recidivism' (p263) and public protection (Worrall and Hoy, 2005) did not result in participants giving more punitive reasons for entering the profession. Rather, Annison et al. (2008) demonstrate that from a list of 12 relevant factors associated with reasons for applying to do the DipPS, participants in both studies ranked 'working with people' as the main factor followed by 'helping offenders' and then 'career development' as third. Annison et al. (2008) concluded that consistency between responses in both studies suggest 'an apparent persistence of the traditional humanistic values of the probation service' (p263).

In a similar study of practitioners in training, but this time using a repeatmeasure design with two cohorts (of trainee probation officers - TPOs) from four probation areas, Deering (2010) issued a self-completion questionnaire at the beginning, midpoint and towards the end of training - designed to capture any fluctuation in beliefs and values over this period. In contrast to Eadie and Winwin Sein's (2004) study, which used a 12-factor ranking scale, Deering (2010) used a series of open questions to explore reasons for entry and perceptions of the probation role. Like Knight (2007) and Annison et al. (2008), Deering found that the main attraction to probation appeared to be 'Content/interest in job/job satisfaction', closely followed by 'Helping/working with people/making a difference' (Deering, 2010:15). Coming third, and perhaps supporting the collated evidence by Annison et al. (2008), was 'Having a career' (Deering, 2010: 15). That said, a question on what sorts of values are required for the probation role revealed that TPOs had a preference for three, otherwise classic, social work dispositions (grouped into similar types): 'Belief in people's ability to change... Commitment to anti-discriminatory practice... [and] Being empathetic/nonjudgemental' (Deering, 2010: 16).

Using a series of Likert scales designed to measure attitudes towards punishment, rehabilitation and the use of prisons, Deering (2010) found that majorities in both cohorts disagreed with the statement: 'The job of the probation officer is primarily to deliver punishment in the community' (ibid: 17). On rehabilitation, Deering (2010) shows that overwhelming majorities (Cohort A: 85\%; Cohort B: 91\%) agreed with the statement: 'Probation officers should concentrate on rehabilitating individuals on supervision back into the community' (ibid: 17). Similarly, $99 \%$ of both cohorts agreed with the statement: 'With appropriate assistance and supervision, individuals can change and lead crime free lives' (ibid: 18). On the use of prisons, Deering (2010) reveals that majorities in both cohorts agreed with the statement: 'Prisons should be reserved for dangerous and violent criminals' (ibid: 18). Interestingly, Deering (2010) found no statistically significant change or noticeable variation in responses from TPOs over their two-year period of training, which suggests that new entrants 
into the probation service perhaps come with particular values, beliefs and attitudes already embedded. But although a belief in rehabilitation comes out strongly, Deering (2010) also found that public protection (as a goal of probation) also featured in several comments from participants. That said, evidence from trainees and newly-qualified staff presented here suggests that, on the whole, attitudes towards punishment and rehabilitation seem to align more with traditional social work values; therefore hinting at the presence of particular dispositions in these penal agents.

\section{'Ideal types' of penal agent}

For more experienced penal-professional agents employed in practice, studies suggest that whilst it is possible to identify certain 'types' of practitioner, socialwork values (such as social justice and a belief in rehabilitation) often form the axis from which persistent styles of welfare-oriented practice seem to stem. In a qualitative study of occupational cultures within the probation service, Worrall and Mawby (2014) interviewed 60 former and current probation workers between 2010-2011. The results of their study show that whilst 'different probation worker cultures co-exist' (ibid: p347), they often share common values such as: 'a belief in the possibility of change... a faith in both offenders and colleagues...[and] an ethos of service' (ibid: p349). Worrall and Mawby (2014) identified three 'ideal types' of probation worker: 'the lifer', 'the second careerist' and the 'offender manager' (p351).

Taken in turn: 'the lifer' is typically over 40, been employed in the probation service for the majority of their working life, and often regards probation more as a vocation. Most have a social work qualification (CQSW) and most take a social work approach with a shared belief in the currency of therapeutic relationships between offender and probation worker. Not completely dissimilar in approach, 'the second careerists' form a category of worker previously employed in non-probation jobs, but drawn to probation by their motivation to 'make a difference and use their transferable people skills' (Worrall and Mawby, 2014: 351). This group is largely made up of ex-health, social services, armed forces, mature students, police and teaching personnel. They also share a belief in the importance of relationships between probationer and practitioner. Interestingly, whilst the third category 'offender managers' shared much by way of primary motivation found in accounts from lifers and second careerists, Worrall and Mawby (2014) noticed that they perceived the probation role itself in three distinct ways: (a) that more emphasis was placed on computer-based risk assessment instead of individual work with offenders; (b) that most contact was office-based rather than home visits; (c) that interagency work was accepted as 'essential and uncontentious' (p351-352). Most 'offender managers' were under 40 , and the majority undertook trainee probation officer 
training (TPO). Worrall and Mawby (2014) found that this particular 'ideal type' perceived a certain 'pragmatism' (p352) in working for the public sector; one that seemed to emphasise the importance of job security and status in professional life. Other observations of this group include them having a 'public protection ethos with little investment in social work culture' and 'some ambivalence about 'the relationship" (ibid: 352). Indeed, it is perhaps interesting to note that notions of public protection are referred to more by younger trainees than experienced staff; similar findings, as we have seen, also emerged in Deering's (2010) more specific study of TPOs. That said, Worrall and Mawby (2014) contend that below the surface interpretation of participant responses, 'offender managers' did seem to possess a deeper and more 'principled rehabilitative approach to working with offenders' (p352). Therefore, the obvious charge that younger trainees might possess more punitive dispositions requires further and deeper analysis before conclusions are drawn.

In essence, the evidence here suggests that despite differences in 'ideal types' of practitioner, the majority of penal agents appear to share common sets of values and principles. And whilst the desire to 'make a difference' and 'faith' in rehabilitation emerge as motivating factors in choosing a probation career, crucially it would appear that more welfare embedded dispositions seem to persist across different cohorts of penal agent.

\section{Comparing English and Scottish penal agents}

Recent studies of probation officers in England (see Robinson et al., 2013) and criminal justice social workers in Scotland (see Grant and McNeill, 2014a; 2014b) have attempted to explore ways in which practitioners conceptualise 'quality' in the routine work they do with offenders. In doing so, these studies also revealed the exercise of values and attitudes in everyday practice that suggest the presence of particular dispositions in penal agents. Both studies mentioned here are linked in that the Scottish researchers - Grant and McNeill (2014a) - gained permission from Robinson et al. (2013) to replicate elements of their English study in a Scottish site. Robinson et al. (2013) conducted a study involving 116 participants (a mix of probation staff) from three probation trusts in England; Grant and McNeill (2014a) conducted a study of 25 criminal justice social workers from one of the largest local authority social work departments in Scotland.

Whilst using focus groups as the primary source of data, both studies also used a ranking exercise to investigate the order of items that practitioners felt were most associated with delivering 'quality' offender supervision. Somewhat strikingly, results from both studies showed perfect symmetry in the grading of the first five items selected by participants (see Table 1). These findings support 
results from Annison et al. (2008) who demonstrate that penal agents often align their work with more relational and 'humanistic' values.

Table 1: Ranking Exercise: Scottish and English Data

\begin{tabular}{l|l|l}
\hline Top 5 Items associated with 'quality' supervision & $\begin{array}{l}\text { Scottish Study } \\
\text { (maximum possible } \\
\mathrm{n}=25)\end{array}$ & $\begin{array}{l}\text { English Study } \\
\text { (maximum } \\
\text { possible n=116) }\end{array}$ \\
\hline Really engaging with the individual & 12 & 52 \\
Reducing risk & 9 & 51 \\
Having enough time to work with individuals & 8 & 50 \\
Responding to the individual's changing needs / & 8 & 36 \\
situation & & 32 \\
A relationship based on mutual trust / respect & 7 & \\
\hline
\end{tabular}

Findings from these Scottish and English studies were merged by Grant and McNeill (2014b) in a comparative analysis, where seven dominant and convergent themes emerged in relation to quality in community supervision. These include: the significance of good relationships between offender and practitioner; the overall need for adequate resources (in both sites); the importance of exercising flexibility and discretion with cases; the surprising inconsequentiality of national policy guidance; the use of skills, knowledge and values; the importance of having good support from managers; and the use of outcome-oriented indicators of progress (capturing incremental change recognised as important by practitioners). Whilst these findings are not completely unexpected within a Scottish context where practice cultures are thought by some to be infused with a long history of welfarism embedded within legislation, policy and civic culture (see Duff and Hutton, 1999; McNeill, 2011), the same might not be said for English findings that emerge from a system that operates, others argue, from a more punitive penal axis (McNeill and Robinson, 2011). That said, claims of a possible de-tartanisation of Scottish policy (McAra, 2008), that is to say a convergence in penal policy between Scotland and the rest of the UK, stands against emerging counter claims of re-tartanisation (a divergence in policy), with Scotland following a more socially democratic and less punitive approach to justice than England - according to some (McNeill, 2011). Recent commentary however, calls for a more nuanced understanding of convergence and divergence in penal policy (See Mooney et al., 2015), where Scottish 'distinctiveness' is perhaps less clear cut than first thought. But notwithstanding these important policy concerns, what these comparative findings show here is that penal agents who are trained by different routes, who occupy different penal contexts with different organisational structures including separate arrangements for offender supervision in both jurisdictions have, it would seem, a striking degree of similarity in the values and principles (and therefore dispositions) that underpin their everyday practice. 
By way of conclusion to this first part of the article, it is perhaps important to note that this section intended to capture elements of existing research where practitioner dispositions have featured amongst other key findings. This is by no means an exhaustive review. My intention here is simply to highlight empirical areas that hint at the potential for conceptual development. The data seems to indicate that practice cultures, and therefore occupational behaviours, are underpinned by more than just knowledge and skills required to do the job; practice appears to be guided by other factors such as inculcated values and principles. But we still know little about when, where or how these more subjective elements are forged and embedded in penal agents. The data also intimates that particular types of people seem to be attracted to penalprofessional work in community settings (those committed to 'making a difference'), and these people appear capable of maintaining their welfare-based values and principles despite working in different penal contexts. The data hints at the existence of particular dispositions that seem durable, but perhaps underplayed in existing research. Another crucial aspect that we know very little about is the relationship between penal agent and punitive context; indeed, none of the studies in this section explored this in any great depth. What is clear, however, is that our understanding of community-based penal agents is in its infancy, with very little conceptual analysis to help explain some of these emerging observations. So, whilst the empirical lacuna requires further research into more complex and nuanced areas of community-based practice cultures such as the impact of practitioner backgrounds, early education and formative experiences, the conceptual lacuna requires, at least, a manageable starting point. With the latter in mind, the remainder of this article will attempt to make sense of how practitioner dispositions are forged in penal agents and how they might be affected by the occupational and punitive contexts they find themselves in. For this we turn to the explanatory potential of Bourdieu's concepts of habitus and field.

\section{Habitus}

As one of Bourdieu's most enduring concepts, habitus is best described as a 'schemata of perception, appreciation and action' (Bourdieu, 1990: 14). The habitus of an agent represents a deeply embedded set of dispositions that people embody, transpose and exercise throughout their lives. Historically-inculcated through social absorption, habitus embodies the beliefs, desires, understandings and knowledge that shape how agents might think, feel and act (Bourdieu, 1994). These dispositions have a 'structured and structuring structure' (Bourdieu, 1994: 170), where the agent is both erstwhile shaped, whilst having capacity to actively shape at the same time. 
The formation of primary habitus within the agent is described by Bourdieu as the progressive grafting of layered schemata from 'pedagogical labour with no precedent' (Bourdieu and Passeron, 1977: 42). Put another way: agents are born without habitus, but acquire early dispositions mainly from familial experience and immediate surroundings. Dispositions are then shaped by gradual exposure to society where a baseline character is fashioned. Over time, the agent will deploy their constituted body - now loaded with dispositions and generative capacities for action - into the social world where the agent now seeks meaning and 'reasons for being' (Bourdieu, 2000: 241).

But whilst Bourdieu (2000) suggests that the configuration of objective conditions can become internalised 'progressively and imperceptibly' (p11) by agents at different points in their life, the extent to which early inculcated dispositions might have contributed to a punitive shaping of our penal agents in their childhood years is not found in the attitudes expressed by adult penal agents in studies of penal agents referred to in this article. Grant and McNeill (2014b), for example, demonstrate that both Scottish and English penal agents expressed strong alignment with values of social justice and principles of rehabilitation (also shown by Annison et al., 2008; Deering, 2010: Worrall and Mawby, 2014). Interestingly, despite the fact that the majority of participants in these studies would have been exposed to multiple penal turns resulting from, as some authors suggest, the onset of late modernity (Garland, 2002); the emergence of risk society (O'Malley, 2010); the impact of post-modernity (Simon, 1993); the arrival of the 'exclusive' society (Young, 1999), or the rise of the neoliberal 'penal state' Wacquant (2009), surprisingly little evidence of overtly punitive orientations were found. It may be suggested, albeit speculatively, that penal agents perhaps absorbed more welfare-oriented dispositions at the primary stage through particular familial practices and early experiences of schooling; although any evidence of this is currently absent from literature, and therefore necessary before any specific claims are made.

Yet, the history of probation itself suggests a lineage of particular 'types' of practitioner stemming initially from $19^{\text {th }}$ Century religious or missionary sources - where individuals were required to demonstrate the pre-existence of moral 'qualities' (Jarvis, 1972). Early commentators on probation's inception and development refer explicitly to the dispositions expected of such staff: preferably educated in social work; some experience of case work; and crucially, to be of good character - with sympathy, tact, personality and resourcefulness (Trought, 1927; Le Mesurier, 1935). These requirements are not completely dissimilar to more contemporary understandings and perceptions of the probation role by students and newly-qualified staff (as demonstrated by Eadie and Winwin Sein, 2004; Annison, 2006). But on the acquisition of more specialised knowledge, Bourdieu (1984) directs the analyst to examine the subsequent grafting of 
dispositions upon existing primary schemata via more proscribed methods of instruction such as education and training. This stage is marked by the acquisition of a secondary habitus, and one where we have more by way of empirical evidence to demonstrate the process.

\section{Secondary habitus}

A secondary habitus can, according to Wacquant (2014), be described as 'any system of transposable schemata that becomes grafted subsequently, through specialized pedagogical labor' (p5). The distinction therefore between primary and secondary habitus relates to its mode of absorbsion or immersion. For Bourdieu and Passeron (1977), the grafting of secondary habitus is less experiential and more didactic in form and method. In other words, it occurs through more structured activities such as schooling or university education.

However, the history of tertiary education for penal agents in the UK has not been without tensions. Explicit political intervention, according to some, marked a theoretical and practical shift in the purpose and structure of higher education for English and Welsh practitioners (see Burke, 2010; Knight and White, 2001; Nellis 1999, 2001; Senior, 2000). Included in attempts to recast a more punitive approach to community punishment (Nellis, 2005; Raynor and Vanstone, 2007) was the introduction of a new Diploma in Probation Studies (DipPS) for English and Welsh penal agents in 1998 (then under a new Labour government). This replaced a longstanding relationship between social work education and probation (where all probation officers were once qualified social workers) (see Annison et al., 2008; Gregory, 2007; Knight, 2002). This is an important divergence to note. Probation had traditionally borrowed knowledge and techniques from social work which, according to Durnescu (2012), 'enhanced the professional status of probation... and helped probation officers to build up their legitimacy and public status' (p179). Yet a paradox emerged in the training of penal agents in the early 1990s where it was suggested that social work education was, as a form of specialised pedagogical labour, simply not specialised enough (Home Office, 1989a; 1989b). Subsequent guidance (provided by the Central Council for Education and Training in Social Work) such as Paper 30: The Requirements and Regulations for the Diploma in Social Work (1991), Training for Social Work Practice in the Criminal Justice System (1992), and Creative Practice Teaching Materials for Probation Placements (1995), all sought to fortify a more robust curricula for emerging penal agents. But despite these efforts, social work education failed to shape a more punitive style of penal agent required for a tougher looking probation service. But in Scotland, social work education retained its purchase on training future penal agents, which remains so today. 
Scottish social work education continues to be marked by its promotion of social justice; of challenging structural inequality; of its faith in change and rehabilitation; and all marked by its strong association with anti-discriminatory practice (Smith and Whyte, 2008). In contrast, the Diploma in Probation Studies for England and Wales removed any significant reference to social justice or welfare principles in its curricula, opting instead for more attention on public protection, risk, and behavioural interventions (Deering, 2010; Eadie, 2000; McGowan, 2002). That said, the Diploma in Probation Studies drew on similar theoretical strands found in social work education such as law, criminology and psychology (Nellis, 2001); although critics suggest that DipPS courses appeared to do this with more emphasis on 'how' to do the job, rather than a more reflective 'why' (Goodman, 2012: 65; see also Treadwell, 2006). Scottish training, on the other hand, remained (and remains) less correctional - preferring an approach steeped in more reflective teaching on the why as well as the how.

Despite following different training routes, the evidence here suggests that wholesale reshaping of habitus (by secondary means) towards a more punitive set of dispositions has not occurred in penal agents from either jurisdiction. This appears to be the case, as we have seen, from evidence gathered on agents whilst in training (Eadie and Winwin Sein, 2004; Annison, 2006; Knight, 2007; Deering, 2010); and also found when penal agents are newlyqualified or experienced practitioners (Robinson and McNeill, 2004; Robinson et al., 2013; Grant and McNeill, 2014a; Worrall and Mawby, 2014). These latter findings are made all the more significant as they would appear to suggest that existing dispositions (possibly forged at the primary stage; presumably buttressed at the second) are somehow able to transcend the broader punitive context in which agents are situated. The grafting of secondary habitus would appear in itself to have limited impact on punitive attitudes; although if anything, as Worrall and Mawby (2014), Deering (2010) and Annison et al. (2008) show, the process of specialised pedagogical labour may account for more pragmatic impressions of probation roles and tasks (as found in responses from more recent entrants into the profession).

As a set of deeply embedded values and principles, perhaps inculcated well-before any decision is made to enter probation services, the generative capacity of these dispositions might offer penal agents a certain distinction or advantage in a professional field subject to constant penal change (discussed below). For as Grant and McNeill (2014b) show in their comparative analysis, penal-professional agents in the UK tend to indicate a preference for discretion and a need to respond creatively to each individual case. This often includes deviation from national standards and other policy documents relating to how practice ought to be done; therefore suggesting the presence of 'counterhegemonic' resistance amongst some practitioners who appear to be driven more 
by values and beliefs (Carey and Foster, 2011) and less by policy and procedure (Evans and Harris, 2004). But this analysis is perhaps too arbitrary. Practitioners who attempt to navigate through competing objectives and organisational pressures by adopting transgressive methods are perhaps engaging in what Mawby and Worrall (2011) refer to as a controlled form of risk-taking. In their analysis, Mawby and Worrall (2011) use the concept of 'edge work' to explain how some probation staff are able, and sometimes allowed - though not formally acknowledged by management - to partially transcend policy and procedures on the assumption that positive outcomes will be achieved through alternative, less proscribed means. Indeed, by employing degrees of creative agency suggests that practitioners may also have active capacities to prevent external punitive discourse from drilling too deeply into their habitus. This is important for Mawby and Worrall (2011), as they argue that probation cultures, and by implication probation practices, have a strong lineage where the professional identities of practitioners are aligned to particular values and principles that help to guide practice in creative ways. Indeed, drawing on a broad range of national and international research on social workers' experience of employment, Fenton (2012) argues that when values and behaviours of practitioners are discordant (typically when practitioners are unable to fulfil their desire to 'help'), agents often experience disjuncture and ethical stress. Fenton (2012) suggests that a correlation exists between high levels of ethical stress and practitioners having little job satisfaction (with some planning to leave the profession altogether). Extending this analysis to penal agents, particularly probation officers in England and Wales, who, argue some, share similar skill-sets to social work (Raynor and Vanstone, 2015), then perhaps we might expect to see similar patterns of disjuncture when values (dispositions) and behaviours (actions) become discordant when probation officers feel unable to 'help'. But we have limited evidence at present on habitus in practice, at least in terms of communitybased penal agents. Nevertheless, we can say, as Fenton (2012) also demonstrates, that for desistance to be supported among offenders, evidence suggests that practitioners must be able to work in ways that are congruent with their values, e.g. being able to build genuinely empathetic relationships, having faith in rehabilitation, striving for social justice and equality, demonstrating antidiscriminatory practice at all times (see McNeill et al., 2005; McCulloch, 2005). It would seem, therefore, that dispositions matter; and perhaps in ways that we have previously underplayed.

But according to Bourdieu (1997), 'Dispositions are subject to a sort of permanent revision, but one that is never radical, given that it operates on the basis of premises instituted in the previous state' (p161). From this we could infer (as suggested elsewhere by Grant and McNeill, 2014b) that perhaps the 'type' of person who enters social work or probation is likely to have, in the first instance, ways of thinking, beliefs and ideals that align with notions of welfare, social 
justice and rehabilitation. And perhaps these deeply inculcated layers of ethical or moral schemata help the penal agent to resist the intrusion of external punitive discourse on the purpose and practice of punishment. Indeed, whilst the evidence presented so far in this article suggests that welfare-oriented penal practices are affected, or perhaps guided by a durable internal habitus, no single UK study goes far enough to examine the relationship between the habitus and the field of practice in which agents operate. The social action or practice of the agent, according to Bourdieu and Wacquant (1992), is affected both by internal configuration of dispositions and external influence of objective conditions. The relationship between the two is explored in the next section.

\section{Field}

To reach a deeper understanding of habitus in practice, Bourdieu (1980) insists that we examine the objective conditions in which practice cultures are situated. Put another way: the mere examination of habitus alone, according to Bourdieu, ignores the impact of 'settings that inculcate, cultivate and reward distinct but transposable sets of categories, skills and desires... [spaces that can be] fruitfully analyzed as sites of production and operation of habitus' (Wacquant, 2014: 4; Bourdieu, 1987, 1999). These settings are described by Bourdieu as fields which may be defined for analytical purposes as particular social spaces that possess a 'network, or configuration, of objective relations between positions' (Bourdieu and Wacquant, 1992: 97). The field itself can reorient the habitus of agents along particular trajectories of practice mediated by prevailing doxa - a pre-reflexive sense of intuition or taken-for-granted assumptions that Bourdieu described as 'a set of fundamental beliefs which does not even need to be asserted in the form of an explicit, self-conscious dogma' (Bourdieu, 2000: 16). Bourdieu deployed his concept of field on major topics such as education (Bourdieu and Passeron, 1977) and culture (1984), but turned his lens on the legal corpus in 1987 with a specific examination on how the 'world of law' is constituted (in this case, the French juridical field). For our purposes, this is perhaps the most proximate analysis of a justice-type setting that Bourdieu provides.

By applying the concept of field on the French legal system, Bourdieu (1987) exposed the internal characteristics and structuring structures of a distinct legal-professional culture. His work uncovered a body organized around legal values - infused with tradition and history, and reinforced by deeply embedded practice cultures. Yet interestingly, because of a strong configuration in field conditions (buttressed by history and tradition) and durable dispositions of the agents within it (positions of high status conferred by education and title steeped in legal values), legal agents are capable, according to Bourdieu, of resisting external interference (e.g. political interference in legal processes). But it is important to stress here that Bourdieu's focus was not on the penal agents who 
might, and often do, intersect with the 'legal world' as part of the process of delivering community justice; he made no reference to social workers or probation officers, only those agents directly involved in the administration of law. At first glance, the exclusion of community-based penal agents in his 1987 article might reflect the fact that the French system of probation had not, at that point, formed a distinct identity as professional group until much later (see Pelissier and Perrier, 2008). However, Bourdieu was interested in exploring the law itself as a constitutive force - thereby requiring a more specific analysis of key players involved in exclusively legal processes. Nevertheless, some scholars have, more recently, employed Bourdieu's concept of field to better understand the practice of agents based in other sub-fields of justice such as prisons.

In perhaps the most comprehensive example of field analysis on penal agents to date, Lerman and Page (2012) conducted a large scale comparative study of prison officers in two American states. Amongst their findings, Lerman and Page (2012) discovered that prison officers in California were more likely to express punitive attitudes towards the purpose of imprisonment than officers working in similar prison environments in Minnesota. These differences were thought to reflect the broader penal-punitive orientation of state-level policy, where California is believed to be tougher in its approach to punishment. Yet, despite divergence in attitudes towards the purpose of imprisonment, both sites revealed that prison officers were more likely to support the use of rehabilitative programmes or interventions if they resulted in outcomes such as reduced prison violence or other situated benefits for staff. This suggests that the influence of state-level policy on penal dispositions of agents is perhaps more complex than a straightforward causal effect. Based on their findings, Lerman and Page (2012) proposed a hybrid embedded work role perspective which asserts that whilst officers are rooted in their prison-based roles and within the broader penal field at the same time, general punitive attitudes towards incarceration are perhaps influenced by state-level penal contexts, but attitudes towards the purpose of specific rehabilitative programmes or interventions are perhaps mediated more locally by organisational context and professional role. Lerman and Page (2012) developed the notion of bi-dimensionality to explain that 'officers' penal orientations have both an ideological and a programmatic dimension' (p513). In short, expressions of support for rehabilitation emerge when the potential for better working conditions are realised (in prison sites); whereas punitive attitudes towards the purpose of imprisonment appear embedded more in broader social contexts of penality. However, what Lerman and Page (2012) achieve here is crucial for our purpose: they employ a framework of analysis that helps to illuminate the complex intersection of penal agent and penal field. This relationship is not straightforward (as shown), but this is precisely why a sociology of community-based penal agents is necessary to explore whether an 
embedded work role perspective, for example, has traction with other types of penal agent in other types of penal environment.

Notwithstanding, the concept of field has been used in other studies of penal agents where results suggest a more complex picture of the relationship between social context and penal agent. For example, in a Scottish study that used the concept to understand practice behaviours of criminal justice social workers involved in writing court reports, McNeill et al. (2009) found that despite state-level pressure on these penal agents to focus on risk and public protection in their assessments, practitioners often focused more on exploring 'character, attitudes, motivation to change and likely compliance with community sanctions' (p428). In other words, practitioners seemed more interested in assessing offender attributes that would indicate, perhaps, the likelihood of more meaningful engagement with community supervision thereby benefiting penal agents in their everyday work (by having more compliant service users). Whilst this study was conducted with communitybased penal agents in Scotland, the findings are not entirely dissimilar to Lerman and Page's (2012) embedded work-role perspective, where practitioners express less punitive attitudes in situations where they stand to gain from professional investment in rehabilitative ideals. But unlike Lerman and Page (2012), this study did not focus on attitudes towards the purpose of community-based punishment; therefore any comparison is limited. Interestingly however, more explicit tensions are found in other examples of research where penal agents seem to demonstrate completely contradictory behaviours such as being simultaneously punitive whilst being committed to rehabilitation at the same time - such as American parole officers (see Lynch, 2000; also Werth, 2013). These tensions are also evident in European contexts where agents have competing accountabilities both to offenders (who they want to support) and to the court (who they must report to) (see Bauwens et al., 2012). But there is also evidence of emerging resistance to proscribed correctional methods in Europe. In Sweden, for example, Persson and Svensson (2011) found that probation officers seldom used risk assessment tools, despite organisational guidance advising them to do so. Persson and Svensson (2011) suggest that Swedish probation officers might be exercising a type of 'professional logic' (p96) where discretion and autonomy are seen as crucial, perhaps protective, components of probation as a profession. But any attempt to mediate the dispositions of penal agents in each respective penal field remains a crucial area for further research.

Indeed, while this article is limited in its scope to provide a full Bourdieusian field analysis of UK penal agents (including attitudes towards the purpose of community-based punishment), we can however trace some distinctive features of the space in which community punishment is practiced. It 
could be argued, for example, that penal agents compete for a monopoly on the rehabilitation of offenders as a distinct mode or dimension that separates their purpose from that of police, prosecutors, solicitors and judges (each with their own stake in the field). However, any claim on distinction is perhaps tempered by organizational drives to increase and embed more inter-agency working between penal agents due to increasing concerns about public protection; for example, some claim that rehabilitative roles between the police and probation or criminal justice social work have become increasingly blurred (see Nash, 2008). This has led to suggestions of a 'policification' (Kemshall and Maguire, 2001) of probation or the emergence of 'polibation' officers (Nash, 1999; 2008). Roles and tasks between the police and probation in areas such as sexual offending seem to be increasingly enmeshed, as practitioners in both fields now exercise surveillance, intelligence gathering and monitoring techniques as part of their public protection duties. Nash (2008) highlights, for example, that the police now enjoy active involvement in the case management of offenders through multiagency public protection arrangements (MAPPA). But whilst some roles and tasks might be merging between different types of professional, the practice cultures, values and principles that underpin the daily work of penalprofessional agents are perhaps underplayed in what appears to be, on the surface at least, a shift towards more correctional and control-based practice in some aspects of offender management. But due to a lack of UK research exploring the field conditions of these particular practice behaviours, means that the relationship between penal agents and penal contexts remains ripe for analysis.

But central to Bourdieu's conception of field is that it is organized around particular practice cultures; cultures where behaviours, procedures, values, assumptions and functions have their own particular relations and shared practices - quite specific to the field itself. Crucially for Bourdieu (1987), the doxa of any field - found in its linguistic, social and psychological practices - has a determining influence on practice cultures within it. The habitus of penal agents in a legal setting, according to Bourdieu (1987), reflects the deeply embedded structure of traditions, discourse and history of the legal world itself. Building on this, we find similar evidence of doxa underpinning practice cultures of probation and social work in relation to expressions of principles and values that agents articulate as if they were taken-for-granted qualities. The habitus of penal agents would appear to reflect the longstanding traditions, discourse and history of probation work itself - that is to say, participants in most studies expressed a consistent leaning towards the popular probation refrain of advise, assist and befriend (Probation of Offenders Act 1907). It could be said that established probation doxa - that which is deeply embedded in its history and tradition may somehow mediate the welfare-oriented dispositions of current staff; thereby offering capacities for resistance to external pressure by its hold on particular 
knowledge, skills and values that enable penal agents to mark their own position of advantage or distinction within the broader justice field. So here we see the struggle, as demonstrated clearly by McNeill et al. (2009), of penal-professional agents who, by accumulating capital as harbingers of rehabilitation (loaded with history and tradition), also strive to gain legitimacy and traction within the competitive and status-laden justice field (see McNeill, 2013).

Yet as mediators of habitus, as Bourdieu (1987) would suggest, the Scottish and English fields of criminal justice appear less successful in shaping more punitive dispositions amongst penal agents involved in the community side of punishment. Nearly all studies presented in this article demonstrate that despite a succession of penal turns, and despite multiple 'transformations' in service delivery, both English and Scottish penal agents seem capable of retaining their value-based dispositions in spite of occupying similar positions in punitively divergent systems. Building on, and perhaps subverting, Garland's (1990) observation that all penal agents (prison and community-based) act as primary conductors of penal culture - in as much as they 'do the most to transform cultural conceptions into penal actions' (p210) - it could be suggested that community-based penal agents are - through the structuring function of habitus - doing the opposite by sustaining a non-punitive penal culture through their commitment to more humanistic forms of practice.

\section{Conclusion}

Critics of Bourdieu often state that his concept of habitus tends to lock practice into definitive patterns of social reproduction, with little scope for creative agency after dispositions are grafted (See Mouzelis, 2004; Akram, 2013). However, Wacquant (2014: 6) argues that scholars have failed to notice that Bourdieu never intended this concept to be applied in rote fashion, he states: 'habitus is a standing invitation to investigate the social constitution of the agent'; and one that should be seen as: 'an empirical prompt: an arrow pointing to the need to methodically historicize the concrete agent embedded in a concrete situation'. In other words, Bourdieu (1997: 162) recognised that habitus can have 'failings, critical moments of perplexity and discordance'. It is therefore incorrect to suggest that dispositions always lead social action in determined ways. More accurately, and to avoid being 'stipulated by analytic fiat' (Wacquant, 2014: 6), Bourdieu suggests that social action must understood and analysed in relational terms between 'conjunction of disposition and position, subjective capacity and objective possibility'. Therefore, the empirical evidence on penal-professional agents in the UK suggests, by the emerging pattern, frequency and convergence of data presented in this article, that they possibly embody certain qualities (for analytic purposes: values and principles) that seem to underpin their approach to practice and social action. But any supposed link between the welfare-oriented 
dispositions and punitive field conditions, would appear to be a more complex area where neither takes precedent over the other.

Using conceptual tools provided by Bourdieu, this article sought to explore existing empirical evidence that pointed towards the presence, of particular dispositions within UK penal agents. By attempting a fresh reading of existing data, the author discovered items of significance and areas of conceptual deficit. These include: (1) that penal agents seem drawn to probation as a career because of their own inculcated dispositions that preclude them towards what they perceive as a 'helping' role; (2) that the influence of primary habitus via pedagogical labour from familial and early school experience remains underexplored; (3) that the grafting of secondary dispositions from higher education - particularly the difference between generic social work education and specialised probation training - requires further analysis; (4) that multiple turns in penal policy appear to have little impact on dispositions; and finally (5) that field conditions of community-based penal agents require deeper analysis to test Lerman and Page's (2012) notion of bi-dimensionality in different sites of punishment.

But exploring the utility of habitus as a concept has been useful for the purpose of this article. As a 'flexible multiscalar notion' it enables the researcher to 'construct the epistemic individual and account for both reproduction and change, conformity and creativity, as well as self-revision' (Wacquant, 2014: 3). In this respect, whilst existing research has hinted at the curious ability of penalprofessionals to resist the influence of punitive discourse in their attitudes, actions and approaches to practice, the concept of habitus has been useful in its ability to help articulate why this might occur, why it persists, and why it appears to transcend different penal contexts. Likewise, the concept of field has illuminated the prospect that penal contexts matter less when occupied by penal agents who possess robust dispositions that reflect humanistic values and principles. Indeed, If we accept Garland's (1990) argument that penal agents act as conduits of penal culture, then it is important for us not just to untangle the complex interplay between those charged with delivering community punishment and the penal context they find themselves in, but we need to further examine the very configuration and construction of penal agents who operate within these arenas too. This article, whilst representing a conceptual starting point, is by no means a conclusion to these emerging questions.

Finally, the broader intention of this article was to initiate a shift in the sociology of punishment towards recognising the importance of the epistemic penal agent 'characterised by those properties (including dispositions) active in the setting under investigation and pertinent to the question pursued' (Wacquant, 2014: 5), as opposed to the empirical individual which often leads to 
reductionist and determinist readings of social action. Indeed, the seemingly convergent and durable practice cultures of penal agents who work in divergent fields of criminal justice demonstrates both the complexity and naivety of formulating the community-based penal agent as a docile being at the mercy of their objective conditions. With deeply inculcated schemata infused by social justice and buttressed by genuine concern for offender welfare, penal agents appear to be neither passive nor compliant. The emerging evidence presented in this article demonstrates that practitioners seem able to endure and persist in punitive arenas, but quite how and why are questions that remain in their empirical and conceptual infancy. Yet perhaps more crucially for Scottish and English practitioners at the moment is just how long their efforts, their dispositions, their resistance, their commitment, can be sustained in the face of ever changing penal conditions.

\section{Acknowledgements}

I am very grateful to Fergus McNeill for helpful comments on earlier versions of this paper.

\section{References}

Akram, S. (2013), 'Fully Unconscious and Prone to Habit: The Characteristics of Agency in the Structure and Agency Dialectic', Journal for the Theory of Social Behaviour, 43: 45-65.

Andrews, D. A. and Bonta, J. (2010), The Psychology of Criminal Conduct, 5th ed. LexisNexis.

Annison, J. (2006), Career Trajectories of Graduate Trainee Probation Officers. University of Plymouth.

Annison, J., Eadie, T., and Knight, C. (2008), 'People First: Probation Officer Perspectives on Probation Work', Probation Journal, 55: 259-272.

Bauwens, A., Robert, L., and Snacken, S. (2012), 'Conditional Release in Belgium: How Reforms have Impacted Recall', European Journal of Probation, 4: 19-33.

Bourdieu, P. (1980), Questions de Sociologie. Editions de Minuit.

Bourdieu, P. (1984), Distinction: A Social Critique of the Judgement of Taste. Routledge.

Bourdieu, P. (1987), 'The Force of Law: Toward a Sociology of the Juridical Field', Hastings Law Journal, 38: 805-853.

Bourdieu, P. (1994), Practical Reasons. On the Theory of Action. Polity Press.

Bourdieu, P. (1997), The State Nobility: Elite Schools in the Field of Power. Polity Press.

Bourdieu, P. (1999), The Weight of the World. Polity Press.

Bourdieu, P. (2000), Pascalian Meditations. Polity Press. 
Grant, S. (2015) 'Constructing the durable penal agent: tracing the development of habitus within English probation officers and Scottish criminal justice social workers', British Journal of Criminology, (accepted July 03, 2015)

Bourdieu, P. and Passeron, J-C. (1977), Reproduction in Education, Society and Culture. Sage.

Bourdieu, P. and Wacquant, L. (1992), An Invitation to Reflexive Sociology. Polity Press.

Burke, L. (2010) 'Probation Qualifications Framework: Getting the Right Balance', Probation Journal, 57: 3-8.

Burke, L. and Davies, K. (2011), 'Introducing the Special Edition on Occupational Culture and Skills in Probation Practice', European Journal of Probation, 3:1-14.

Carey, M. and Foster, V. (2011), 'Introducing 'Deviant' Social Work: Contextualising the Limits of Radical Social Work whilst Understanding (Fragmented) Resistance within the Social Work Labour Process', British Journal of Social Work, 41: 576-593.

Central Council for Education and Training in Social Work (1991), Paper 30: The Requirements and Regulations for the Diploma in Social Work. CCETSW.

Central Council for Education and Training in Social Work (1992), Training for Social Work Practice in the Criminal Justice System. CCETSW.

Central Council for Education and Training in Social Work (1995), Creative Practice Teaching Materials for Probation Placements. CCETSW.

Crewe, B. (2011), 'Soft Power in Prison: Implications for Staff-prisoner Relationships, Liberty and Legitimacy', European Journal of Criminology, 8: 455-468.

Deering, J. (2010), 'Attitudes and Beliefs of Trainee Probation Officers: a New Breed?', Probation Journal, 57: 9-26.

Deering, J. (2011), Probation and the New Penology: Practitioner Reflections. Ashgate.

Ditton, J. and Ford, R. (1994), The Reality of Probation: A Formal Ethnography of Process and Practice. Avebury.

Duff, P. and Hutton, N. (eds.) (1999), Criminal Justice in Scotland. Ashgate.

Durnescu, I. (2012), 'What Matters Most in Probation Supervision: Staff Characteristics, Staff Skills or Programmes?', Criminology E Criminal Justice, 12: 193-216.

Eadie, T. (2000), 'From Befriending to Punishing: Changing Boundaries in the Probation Service', in N. Malin (ed) Professionalism, Boundaries and the Workplace, 161-177. Routledge.

Eadie, T. and Winwin Sein, S. (2004), Probation Officer Development and Retention: A Longitudinal Study. Questionnaire One. Midlands Consortium.

Evans, T. and Harris, J. (2004), 'Street-level Bureaucracy, Social Work and the (Exaggerated) Death of Discretion', British Journal of Social Work, 34: 871-96.

Fenton, J. (2012), 'Bringing Together Messages from the Literature on Criminal Justice Social Work and 'Disjuncture': The Importance of 'Helping', British Journal of Social Work, 42: 941-956.

Garland, D. (1990), Punishment and Modern Society: A Study in Social Theory. Oxford University Press.

Garland, D. (2002), The Culture of Control: Crime and Social Order in Contemporary Society. Oxford University Press.

Goodman, A. (2012), Rehabilitating and Resettling Offenders in the Community. WileyBlackwell.

Grant, S. and McNeill, F. (2014a), 'What Matters in Practice? Understanding 'Quality' in the Routine Supervision of Offenders in Scotland', British Journal of Social Work, advance access first published May 26, 2014, doi: 10.1093/bjsw/bcu056. 
Grant, S. (2015) 'Constructing the durable penal agent: tracing the development of habitus within English probation officers and Scottish criminal justice social workers', British Journal of Criminology, (accepted July 03, 2015)

Grant, S. and McNeill, F. (2014b), 'The Quality of Probation Supervision: Comparing Practitioner Accounts in England and Scotland', European Journal of Probation, 6 : 147-168

Gregory, M. (2007), 'Probation Training: Evidence from Newly Qualified Officers', Social Work Education, 26: 53-68.

Home Office (1989a), Probation Training: Review of Home Office Sponsorship Scheme. Home Office.

Home Office (1989b), Review of Probation Training: Final Report. Home Office.

Jarvis, F. V. (1972), Jarvis's Probation Officers Manual. Butterworth.

Kemshall, H., and Maguire, M. (2001), 'Public Protection, Partnership and Risk Penality: The Multi-agency Risk Management of Sexual and Violent Offenders', Punishment \& Society, 3: 237-264.

Knight, C. (2002) 'Training for a Modern Service', in D. Ward, J. Scott and M. Lacey (eds) Probation: Working for Justice, 276-96. Oxford University Press.

Knight, C. (2007) 'Why Choose the Probation Service?', British Journal of Community Justice, 5: 55-69.

Knight, C. and White, K. (2001), 'The Integration of Theory and Practice within the Diploma in Probation Studies: How is it Achieved?', Probation Journal, 48: 203-10.

Le Mesurier, L. (ed) (1935), A Handbook of Probation and Social Work of the Courts. National Association of Probation Officers.

Lerman, A. E. and Page, J. (2012), 'The State of the Job: An Embedded Work Role Perspective on Prison Officer Attitudes', Punishment E Society, 14: 503-529.

Liebling, A. (2000), 'Prison Officers, Policing and the Use of Discretion', Theoretical Criminology, 4: 333-357.

Lynch, M. (2000), 'Rehabilitation as Rhetoric: The Ideal Reformation in Contemporary Parole Discourse and Practices', Punishment and Society, 2: 40-65.

Mair, G., Burke, L. and Taylor, S. (2006), 'The Worst Tax Form You've Ever Seen? Probation Officers' Views about OASys', Probation Journal, 53: 7-23.

Mawby, R. C. and Worrall, A. (2011), Probation Workers, Their Occupational Cultures. University of Leicester (ESRC summary report).

Mawby, R. C. and Worrall, A. (2013), Doing Probation Work: Identity in a Criminal Justice Occupation. Routledge.

McAra, L. (2008), 'Crime, Criminology and Criminal Justice in Scotland', European Journal of Criminology, 5: 481-504.

McCulloch, T. (2005), 'Probation, Social Context and Desistance: Retracing the Relationship', Probation Journal, 52: 8-22.

McGowan, V. (2002), 'Reflections: The NVQ - A Means to an End?', The Probation Journal, 40: 35-39.

McNeill, F. (2011), 'Determined to Punish? Scotland's Choice', in G. Hassan and R. Ilett (eds), Radical Scotland: Arguments for Self-determination, 128-142, Luath Press.

McNeill, F. (2013), 'Transforming Rehabilitation: Evidence, Values and Ideology', British Journal of Community Justice, 11: 83-87.

McNeill, F., Batchelor, S., Burnett, R. and Knox, J. (2005), 21st Century Social Work, Reducing Re-Offending: Key Practice Skills. Scottish Executive.

McNeill, F., Burns, N., Halliday, S., Hutton, N. and Tata, C. (2009), 'Risk, Responsibility and Reconfiguration: Penal Adaptation and Misadaptation', Punishment $\mathcal{E}$ Society, 11: 419-442. 
Grant, S. (2015) 'Constructing the durable penal agent: tracing the development of habitus within English probation officers and Scottish criminal justice social workers', British Journal of Criminology, (accepted July 03, 2015)

McNeill, F. and Robinson, G. (2011), 'Liquid Legitimacy and Community Sanctions', in A. Crawford and A. Hucklesby (eds) Legitimacy and Compliance in Criminal Justice, 116-137. Willan.

Ministry of Justice (2013), Transforming Justice: A Strategy for Reform. Stationary Office. Ministry of Justice (2015), Proven Re-offending Statistics Quarterly Bulletin: April 2012 to March 2013, England and Wales. Ministry of Justice Statistics Bulletin, 29 January 2015. Ministry of Justice.

Mooney, G., Croall, H., Munro, M. and Scott, G. (2015), 'Scottish Criminal Justice: Devolution, Divergence and Distinctiveness', Criminology and Criminal Justice, 15: 205-224.

Mouzelis, N. (2004), Sociological Theory: What Went Wrong? Diagnosis and Remedies. Routledge.

Nash, M. (1999), 'Enter the Polibation Officer', International Journal of Police Science and Management, 1: 252-261.

Nash, M. (2008), 'Exit the Polibation Officer? Decoupling Police and Probation', International Journal of Police Science and Management, 10: 302-312.

National Offender Management Service (2013), Probation Trust Annual Performance Ratings 2012/13. NOMS.

Nellis, M. (1999), 'Towards "The Field of Corrections": Modernizing the Probation Service in the Late 1990s', Social Policy and Administration, 33: 302-323.

Nellis, M. (2001), 'The New Probation Training in England and Wales: Realising the Potential', Social Work Education, 20: 415-32.

Nellis, M. (2005), 'Electronic Monitoring, Satellite Tracking and the New Punitiveness in England and Wales', in J. Pratt, D. Brown, M. Brown, S. Hallsworth and W. Morrison (eds) The New Punitiveness: Trends, Theories and Perspectives, 167-188. Willan.

O'Malley, P. (2010), Crime and Risk. Sage.

Pelissier, B. and Perrier, Y. (2008), 'France', in A. M. Van Kalmthout and I. Durnescu (eds) Probation in Europe, 349-380. Wolf Legal Publishers/CEP.

Persson, A. and Svensson, K. (2011), 'Signs of Resistance? Swedish Probation Officers' Attitudes towards Risk Assessments', European Journal of Probation, 3: 95-107.

Raynor, P., Ugwudike, P. and Vanstone, M. (2010), 'Skills and Strategies in Probation Supervision: The Jersey Study', in F. McNeill, P. Raynor and C. Trotter (eds.), Offender supervision: new directions in theory, research and practice, 113-129. Willan.

Raynor, P., Ugwudike, P. and Vanstone, M. (2013), 'The Impact of Skills in Probation Work: A Reconviction Study', Criminology and Criminal Justice, advanced access first published on July 14, 2013, doi: 10.1177/1748895813494869.

Raynor, P. and Vanstone, M. (1997), Straight thinking on probation (STOP), Probation Studies Unit Report No. 4. University of Oxford.

Raynor, P. and Vanstone, M. (2007), 'Towards a Correctional Service', in L. Gelsthorpe and R. Morgan (eds) Handbook of Probation, 59-89. Willan.

Raynor, P. and Vanstone, M. (2015), 'Moving Away from Social Work and Half Way Back Again: New Research on Skills in Probation', British Journal of Social Work, advance access first published February 12, 2015, doi:10.1093/bjsw/bcv008.

Robinson, G. (2003), 'Technicality and Indeterminacy in Probation Practice: A Case Study', British Journal of Social Work, 33: 593-610. 
Grant, S. (2015) 'Constructing the durable penal agent: tracing the development of habitus within English probation officers and Scottish criminal justice social workers', British Journal of Criminology, (accepted July 03, 2015)

Robinson, G. and McNeill, F. (2004), 'Purposes Matter: Examining the 'Ends' of Probation', in G. Mair (ed.), What Matters in Probation?, 277-304. Willan.

Robinson, G., Priede, C., Farrall, S., Shapland. J. and McNeill, F. (2013), 'Understanding 'Quality' in Probation Practice: Frontline Perspectives in England \& Wales', Criminology and Criminal Justice. Advance access first published on May 20, 2013, doi: $10.1177 / 1748895813483763$.

Robinson, G. and Ugwudike, P. (2012), 'Investing in 'Toughness': Probation, Enforcement and Legitimacy', The Howard Journal of Criminal Justice, 51: 300-316.

Senior, P. (2000), 'Fact and Fiction: Another Perspective on Probation Training', Criminal Justice Matters, 40: 17-18.

Simon, J. (1993), Poor Discipline: Parole and the Social Control of the Underclass 1890 - 1990. University of Chicago Press.

Smith, M. and Whyte, B. (2008), 'Social Education and Social Pedagogy: Reclaiming a Scottish Tradition in Social Work', European Journal of Social Work, 11: 15-28.

Treadwell, J. (2006), 'Some Personal Reflections on Probation Training', The Howard Journal, 45: 1-13.

Trought, T. W. (1927), Probation in Europe. Blackwell.

Ugwudike, P. (2011), 'Mapping the Interface between Contemporary Risk-focused Policy and Frontline Enforcement Practice', Criminology \& Criminal Justice, 11: 242-258.

Wacquant, L. (2009), Punishing the Poor: The Neoliberal Government of Social Insecurity. Duke University Press.

Wacquant, L. (2014), 'Homines in Extremis: What Fighting Scholars Teach us about Habitus', Body and Society, 20: 3-17.

Werth, R. (2013) 'The Construction and Stewardship of Responsible yet Precarious Subjects: Punitive Ideology, Rehabilitation, and 'Tough Love' among Parole Personnel', Punishment E Society, 15: 219-246.

Worrall, A. and Hoy, C. (2005), Punishment in the Community: Managing Offenders, Making Choices. Willan.

Worrall, R. and Mawby, A. (2014), Doing Probation Work: Identity in a Criminal Justice Occupation. Routledge.

Young, J. (1999), The Exclusive Society: Social Exclusion, Crime and Difference in Late Modernity. Sage. 